\title{
The general procedure of numerical analysis related to a fatigue damage on the cyclically loaded construction
}

\author{
Petr Lehner ${ }^{1}$, Přemysl Pařenica ${ }^{1, *}$, Martin Krejsa ${ }^{1}$, Vit Křivý $^{1}$, Jiři Brožovský ${ }^{1}$, \\ Stanislav Seitl ${ }^{2}$, and Zdeněk Kala ${ }^{3}$ \\ ${ }^{1}$ VSB - Technical University of Ostrava, Faculty of Civil Engineering, Department of Structural \\ Mechanics, Ludvíka Podéště 1875/17, 70833 Ostrava-Poruba, Czech Republic \\ ${ }^{2}$ Institute of Physics of Materials, ASCR, v. v. i., Zizkova 22, 61662 Brno, Czech Republic \\ ${ }^{3}$ Faculty of Civil Engineering, Brno University of Technology, Veveří 331/95, 60200 Brno, Czech \\ Republic
}

\begin{abstract}
The paper presents a general procedure of numerical analysis of the steel structure in case of cyclic loading. The basic recommendations that can be applied to different details, are discussed. The article shows examples of the truss structure loaded with a crane track, but also applicable to other types of constructions. There are basic ideas of the whole process, which is divided into several parts. The beginning of the process is to determine the influence line from the simplified model of the whole structure. A stochastic estimation of the load effect associated with the load history in combination with the influence line is utilized. The complex 3D FEM model for estimation of residual life of the chosen detail is the main result of the analysis.
\end{abstract}

\section{Introduction}

In the structural analysis of steel objects subjected to cyclic stress, it is necessary to assess, among other things, also the fatigue resistance [1-6]. Efficient and sustainable design of these types of structures can be realized by valid codes [7-10] and by appropriate application of available computing software $[4,11,12]$.

Currently, there are specific requirements to predict the residual life of existing steel structures, some of which may have been in operation for decades [13-15]. Some of the original steel riveted structures are still in operative state without major failures. These historic buildings still fulfil their original function.

For this reason, the prediction of the residual life of existing buildings is a significant and ongoing technical problem $[15,16]$. For reliable evaluation of the numerical analysis of the structure or its parts and joints, the actual load data must be available. There are several studies for stochastic reliability estimation and consequent life prediction of various load-carrying elements and structures [3,17-20]. However, there is no generally valid

\footnotetext{
* Corresponding author: premysl.parenica@vsb.cz
} 
calculation methodology based on probabilistic modelling that would be directly applicable to existing structures under the cyclic load.

It is necessary to obtain data about load history for a sufficiently representative period of operation of structures that are repeatedly loaded. Long-term measurements are usually very complicated with large cost [21], so the simulation methods [22] can be used to adequately determine load history in critical details. One of the options can be the calculation procedure that allows the determination of the load history using the MonteCarlo simulation method [23].

The aim of the paper is to present a possible general procedure of assessing fatigue resistance and predicting the residual life of riveted steel structures (for examples see Figs 1a, 1b.) under cyclic loading that could be applicable in the construction industry. Although prerequisites for riveted structures are presented, this procedure can be applied to other steel prefabricated structures with certain changes. The method outlined in this paper is only one of the possibilities of analysis and provides variability of assessment process due to division into several separate parts.

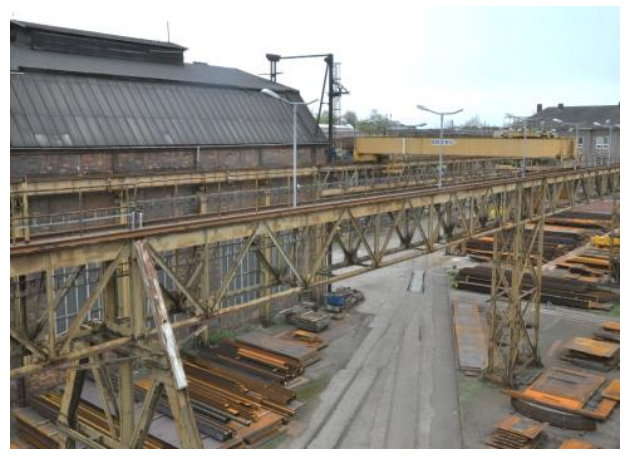

(a)

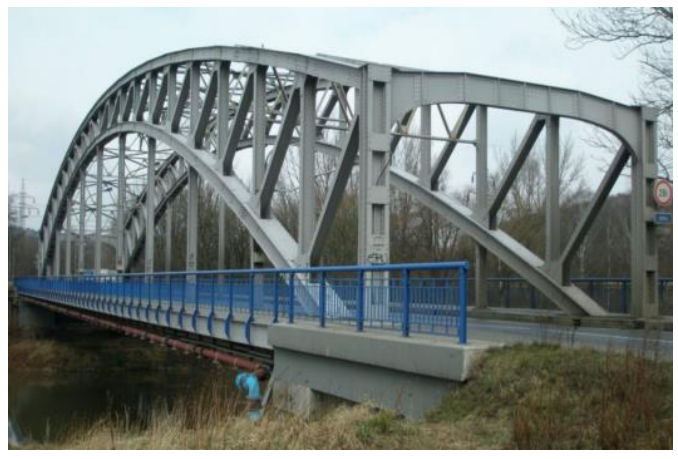

(b)

Fig. 1. Example of steel truss structure supporting the crane (build in 1933) (a), and steel truss bridge under road (built in 1929) (b).

\section{Construction and material assessment}

Several basic investigative procedures have to be realized before the performing of the proper analysis. Firstly, the appropriate determination of the mechanical and strength properties of old steel based on a detailed investigation of structure is needed, which can also serve for a decision about a steel quality, which can replace the existing damaged old steel elements [24]. In this case, it is not important, whether the structure is a steel bridge construction or a support truss under crane runway.

Equally important is the appropriate determination of the load to which the construction has been subjected in its life. This information can be obtained from the expert estimation by the operation technician; in case of the overhead crane, it is usually information about characteristics and number of crane movements during the selected working cycle (e.g. one working shift, distribution of the lifted mass, number of working shifts per one year etc.). In case of a steel bridge under railway or road, the analysis of traffic history is desirable. In both cases, the load can be expressed using deterministic and stochastic parameters, which are used for further calculations.

Knowledge of exact geometrical parameters of the whole structure, detailed dimensions, detection of dangerous places, eventually determination of material affected by corrosion process are a matter of course. 


\section{Simple numerical model}

After the basic initial investigation, the simple beam elements numerical model can be prepared, for example in SCIA Engineering software [25]. On this model, it is possible to apply modern required loads and get a basic idea of the behaviour of the structure. Similarly, the model can be used to identify dangerous elements or parts in terms of exceeding the maximum stress or in terms of another selected limit value (for example see Fig. 2).

The model has to be simple to allow rapid analysis, including the determination of the influence line of any part of the structure and the variable load (overhead crane, vehicle, train, etc.).

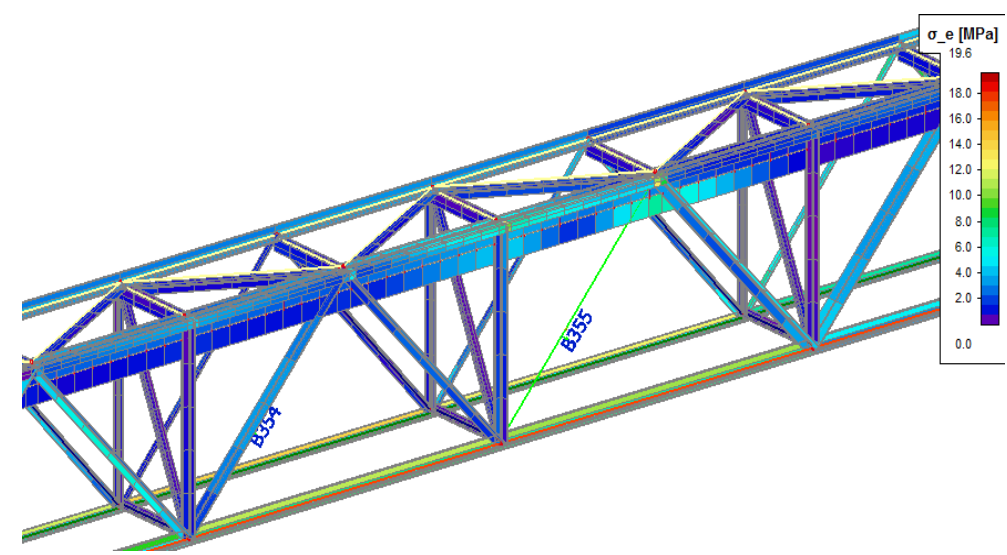

Fig. 2. Example of graphical representation of von Mises stress, which can be obtained from a simple beam elements model of investigated structure.

\section{History of load prediction}

The moving load can be characterized by a time course. For constructions such as crane tracks, the size of the wheel pressures, the number of moving repetitions and the resulting internal forces in the element should be determined. Similarly, for structures under railway or road, time record of passing vehicles and trains regarding their weight distribution must be known.

\subsection{Amplitude of load history}

With respect to the high cyclic fatigue of the elements, it is possible to use the spectrum stress range method. Of course, other standardized procedures can also be used, for example equivalent fatigue load [9]. The spectrum of stress range can be achieved by stochastic analysis using Monte Carlo simulation by entering random input parameters. The result of the analysis is the load history amplitude. This entry can be applied as the load combinations to a detailed model of a specific part or connection after properly sorting.

\subsection{Rain Flow sorting}

The stress range spectrum can be derived from the amplitude of the load history e.g. using the Rain Flow method [26]. This method has been developed in the 1960s and is widely used for fatigue analysis of engineering components. 
Based on this method, the obtained load history amplitude data are reduced to local extremes, so-called peaks and valleys. The differences of the neighbouring extremes are classified into similar categories, and determined by so-called half-cycles, and the Rain Flow Matrix is created. The matrix contains the mean values (Mean) and range of classes (Range) as well as the number of values in each class. As a result, the load combinations can be calculated from the values anytime and then serves as a load value for a detailed model of the part that is supposed to be analysed.

Algorithm that has been developed by the authors includes stochastic load history prediction and rain flow sorting, which allows a quick evaluation of this part of the calculation.

\section{Detailed FEM model}

For the final analysis of residual life of the chosen structure part the model can be prepared in the software ANSYS Workbench [27]. It should be noted that it is possible to use any finite element method (FEM) software, but the ANSYS contains Fatigue module, that is ideal for this type of calculation. The important points that are related to modelling of the specific structures follows.

\subsection{Rivets pretention}

In the case of a riveted structure, it is very important to model the connections appropriately. In addition to precise geometry, it is necessary to assume that there is a certain pretension in the rivets (see example in Fig. 3). Its value needs to be examined in more detail. Too little or too much preload can significantly affect the results of numerical analysis.

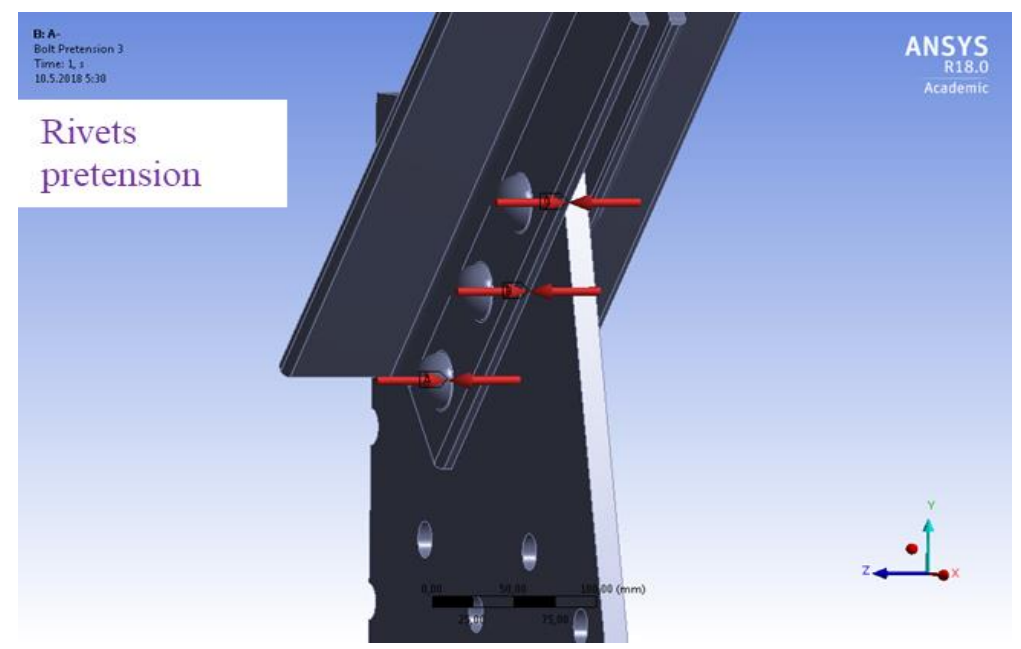

Fig. 3. Example of the model of riveted connection with application of pretension in each rivet.

\subsection{Load combination application}

The load combination is bounded to the number of non-zero classes in the Rain flow matrix. Thus, all classes that have a certain value create a separate load combination. From each combination, it is possible to determine two load cases. 
To calculate the exact value two simple equations are given:

$$
\begin{aligned}
& N_{\mathrm{i}+}=\text { Mean }+ \text { Range } / 2 \\
& N_{\mathrm{i}-}=\text { Mean }- \text { Range } / 2
\end{aligned}
$$

For example, the combination is obtained from Mean value of $26.06 \mathrm{kN}$ and a Range value of $54.28 \mathrm{kN}$, according to the formulas (1) and (2), the load case is $N_{\mathrm{i}^{+}}=80.35 \mathrm{kN}$ and number $N_{\mathrm{i}-}=-28.22 \mathrm{kN}$.

The fatigue calculation must be performed for each load combination corresponding to the maximum and minimum normal force for a given amplitude. Evaluating of stress components can be considered for the equivalent von-Mises stress.

The damage for individual load combinations has to be calculated. This damage is obtained by comparing stress values from a positive and negative case. This is subsequently evaluated.

\subsection{Materials properties by S-N curve}

In fatigue model is needed to select the material characteristics, which can be done with $S$ $N$ curves. The $S$ - $N$ curves can be obtained from laboratory testing of samples taken from the investigated steel structure, see [28].

Curves from the standards [9] or from literature [15] can also be used for specific details (see example in Fig. 4).

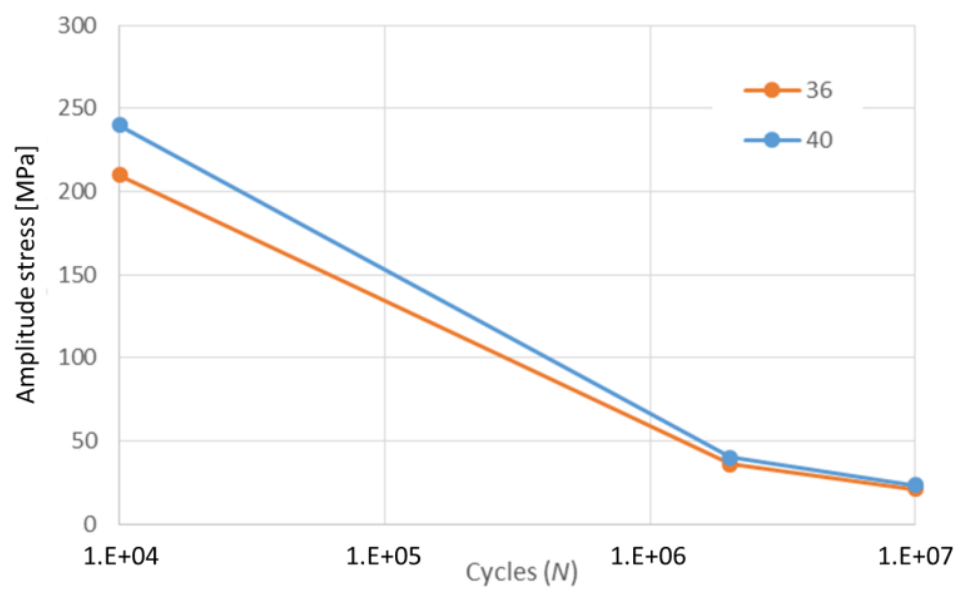

Fig. 4. Example of graph of the magnitude of a cyclic stress (S) against the logarithmic scale of cycles to failure (N). The S-N curves category No. 36 and No. 40 from EC [9].

\subsection{Cumulative hypothesis}

From the individual values of load combinations, it is possible to create a numerical analysis of the selected construction detail. For individual combinations, a particular prediction of fatigue damage can be calculated. This values are inverse to prediction of residual live and all particular damages can be summed up by the cumulative rule, for example Palmgren-Miner Rule [29], Corten-Dolan Rule [30], Kwofie-Rahbar Rule [31]. The resulting damage can be transferred back to the numerical model due to the possibilities of graphical display to allow evaluating dangerous parts of the detail. The residual lifetime of each component of model can be obtained. 


\section{Discussion and conclusion}

The article aims to a general description of the analysis process of the existing steel structure with cyclic load; for example, support constructions under overhead cranes, or bridges under the railway and road.

First step must be in-depth analysis of the entire structure in terms of material, geometry and load history. This information can be collected from the operating technician or longterm traffic record. In terms of modelling, the basis is a simple beam elements model of the entire structure. It serves for locating the most stressed element by the moving load.

After solving the first task, the stochastic analysis of load history can be prepared. This is needed to attain the adequate load combination of the selected part of structure. Fatigue assessment is based on a comparison of calculated stress and material fatigue curves. As cumulative hypothesis for summing of the particular damages is possible to use several rules. The result is the number of load cycles on the specific part, and also the residual life.

The article presents basic recommendations of fatigue assessment. By splitting the analysis into several separate parts, some of them can be replaced by more advanced processes.

This contribution has been developed as a part of the research project GACR 17-01589S "Advanced computational and probabilistic modelling of steel structures taking account fatigue damage" supported by the Czech Grant Agency

\section{References}

[1] Y. Xiang, Y. Liu, Probabilistic Engineering Mechanics. 26 148-156 (2011).

[2] X.W. Ye, Y.H. Su, J.P. Han, Mathematical Problems in Engineering. 2014 1-13 (2014).

[3] J. Vičan, J. Gocál, J. Odrobiňák, P. Koteš, Procedia Engineering. 156 507-514 (2016).

[4] A.F. Hobbacher, Proc. of the Int. Conf. on Advances in Welding Science and Technology for Construction, Energy and Transportation, AWST 2010 (2010)

[5] B. Kühn, M. Lukić, A. Nussbaumer, H. Günther, R. Helmerich, R. Herion, M. Kolstein, S. Walbridge, B. Androic, O. Dijkstra, Ö. Bucak, Steel Construction. 1 94-95 (2008).

[6] B. Åkesson, Fatigue life of riveted steel bridges, (2010).

[7] EN 1993-1-1, CEN. (2005).

[8] EN 1991-3 July, Eurocode 1 - Actions on structures - Part 3: Actions induced by cranes and machinery Eurocode, (2006).

[9] B.E. 1993-1-3:2009, Eurocode 3: Design of Steel Structures - Part 1-9: Fatigue. (2011).

[10] S.B. Hashemi, J. Maljaars, H.H. Snijder, Safety and Reliability - Safe Societies in a Changing World (2018): pp. 2339-2345.

[11] A.J. Sadowski, J.M. Rotter, T. Reinke, T. Ummenhofer, Structural Safety. 53 2635 (2015).

[12] R. Zhang, S. Mahadevan, Journal of Structural Engineering. 127 957-965 (2001).

[13] P. Lehner, M. Krejsa, P. Pařenica, V. Křivý, J. Brožovský, International Journal of Fatigue. 128105190 (2019).

[14] P. Lehner, V. Křivý, M. Krejsa, P. Pařenica, J. Kozák, Stochastic Service Life 
Prediction of Existing Steel Structure Loaded by Overhead Cranes, in: Procedia Structural Integrity, Elsevier, (2018): pp. 1539-1544.

[15] B. Kühn, Procedia Engineering. 66 3-11 (2013).

[16] M.A. Torres, S.E. Ruiz, Engineering Structures. $292183-2192$ (2007).

[17] Z. Kala, Archives of Civil and Mechanical Engineering. 15 1098-1107 (2015).

[18] P. Ghosh, P. Konečný, P. Lehner, P.J. Tikalsky, Computers and Concrete. 19305 313 (2017).

[19] J. Králik, Procedia Engineering. $190472-479$ (2017).

[20] A. Przekop, S.A. Rizzi, Computers and Structures. 84 1606-1618 (2006).

[21] F. Casciati, C. Fuggini, Smart Structures and Systems. 7 349-363 (2011).

[22] W. Punurai, P. Davis, Engineering Journal. 21 1-13 (2017).

[23] N. Metropolis, S. Ulam, Journal of the American Statistical Association. 44335 (1949).

[24] S. Seitl, P. Miarka, P. Janosik, Modelling in Mechanics (2019).

[25] Scia Engineering, Online Dokumentation. (2017).

https://www.scia.net/en/support/downloads/scia-engineer-manuals-tutorials.

[26] C. Amzallag, J.P. Gerey, J.L. Robert, J. Bahuaud, International Journal of Fatigue. 16 287-293 (1994).

[27] ANSYS, ANSYS User Guide. 15317514 (2016).

[28] S. Seitl, P. Miarka, P. Pokorny, L. Kunz, Transactions of the VŠB - Technical University of Ostrava, Civil Engineering Series, (In Press). (2019).

[29] Z. Hashin, Journal of Applied Mechanics. 47 324-328 (1980).

[30] E.W.C. Wilkins, Colloquium on Fatigue / Colloque de Fatigue / Kolloquium Über Ermüdungsfestigkeit, (1956): pp. 321-332.

[31] S. Kwofie, N. Rahbar, International Journal of Damage Mechanics. (2013). 